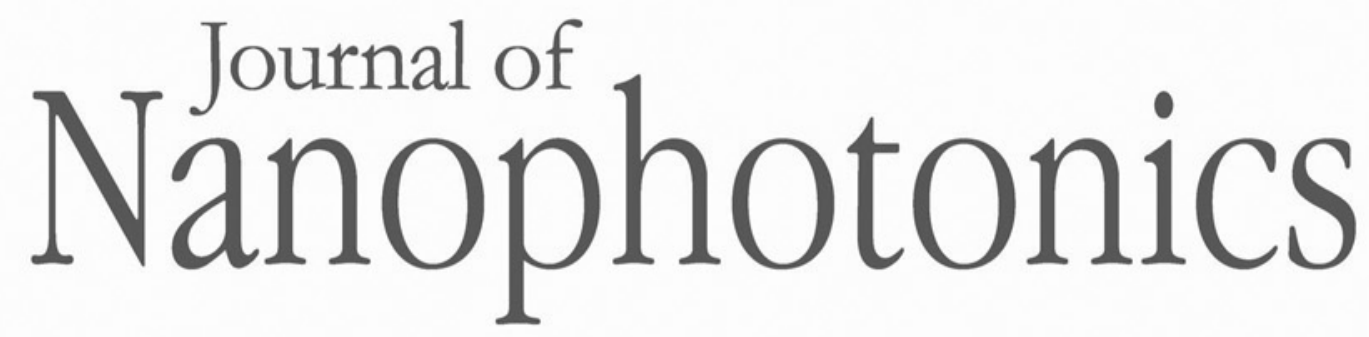

Nanophotonics.SPIEDigitalLibrary.org

\title{
Publisher's note: Journal of Nanophotonics, Volume 11, Issue 1
}




\section{Publisher's note: Journal of Nanophotonics, Volume 11, Issue 1}

The two articles listed below were mistakenly published in Volume 11, Issue 4, of the Journal of Nanophotonics. Both articles now appear in Volume 11, Issue 1, with updated citation identifiers (CIDs). The updated citations appear below:

J. R. Dunklin et al., "Plasmonic extinction in gold nanoparticle-polymer films as film thickness and nanoparticle separation decrease below resonant wavelength," J. Nanophoton. 11(1), 016002 (2017).

M. K. Balyan, “X-ray nonlinear Bragg diffraction,” J. Nanophoton. 11(1), 016003 (2017).

(C) 2017 Society of Photo-Optical Instrumentation Engineers (SPIE) 